\title{
An overview of the use of drugs in palliative care settings worldwide
}

\section{Abstract}

Introduction: To provide an overview of drug use in palliative care worldwide and to identify the most commonly used medicines in palliative care settings.

Methods: Quasi-systematic review. Search strategy: Medline/PubMed, Embase, SCOPUS and Google Scholar were searched utilizing the selected MeSH terms: palliative care, hospice, drug utilization, and prescription patterns.

Results: Overall, it is apparent that there is a significant lack of published literature outlining drug usage in palliative care settings. Twelve sources of information were reviewed from 9 different countries including Austria $(n=1)$, Brazil $(n=1)$, Canada $(n=1)$, Germany $(n=1)$, Italy $(n=2)$, Netherlands $(n=2)$, Norway $(n=1)$, Switzerland $(n=1)$ and USA $(n=3)$, as well as a multinational study comparing 11 European countries. Medication use between countries was similar. The most commonly prescribed classes of medicines included non-opioid analgesics, opioids, laxatives, sedatives and antipsychotics and the most commonly prescribed individual drugs comprised morphine, haloperidol, laxatives and paracetamol.

Conclusions: The literature identifies that there is insufficient evidence to describe and compare what drugs are currently used in palliative care settings worldwide. This is attributed to the lack of recently published articles leading to a large gap in knowledge in understanding drug utilization practices in palliative care. Further research is required to address these gaps in knowledge, and identify medication management issues in palliative care and determining whether there are significant differences in drug management practices.

Palliat Med Pract 2019; 13, 3: 134-141

Key words: drug utilization, palliative care, prescription patterns, hospice

\section{Introduction}

The World Health Organization (WHO) estimates that as many as 40 million people each year are in need of palliative care [1]. Within this setting, timely access to appropriate medical interventions as well as social, psychological, and spiritual support is essential [2]. However, it is reported that one of the largest inequalities in global health relates to the lack of access to symptom relief during palliative care [1]. From a medical perspective, the core principles of palliative care focus on the appropriate assessment, prevention and management of symptoms, including but not limited to pain, nausea, fatigue, and delirium $[2,3]$. Therefore, medications play a particularly integral role in ensuring the comfort of this group of patients. Specifically, an individualised drug regimen is considered imperative in the care of palliative patients, and as such, the subsequent use of pharmacotherapy within this setting is unique [4]. Dosing strategies, formulations and routes of administration differ to those applied within other hospital units, in accordance with each patients needs, and often require unlicensed or off-label prescribing [5]. Kwon et al. highlighted

\footnotetext{
Address for correspondence:

Natalia Krzyżaniak

University of Technology Sydney,

Graduate School of Health (Pharmacy),

Broadway, NSW, Sydney Australia

e-mail: natalia.krzyzaniak@student.uts.edu.au 
that $35 \%$ of prescriptions in an acute palliative unit in the USA were off-label, with the most common including haloperidol, dexamethasone and morphine [6]. Examples of off-label prescribing included the use of anticonvulsants for pain relief or opioids to treat dyspnoea [5]. Due to the importance of ensuring the dignity of patients with advanced diseases, the appropriate and quality use of medicines in palliative care is vital. Medication errors, misuse or interactions may cause unnecessary pain and discomfort, and cause distress to the patient and also to family members and friends. With a reported average of 15.7 drugs prescribed per patient, there is a need to implement a high-quality, safe and rational medicine use process for these patients to ensure optimal levels of comfort and symptom relief [3].

In order to bridge the gap across palliative care settings internationally, WHO established a list of essential medicines in palliative care, intended to guide countries to develop their own medication policies and formularies [7-9]. There have also been studies performed in Australia and Sweden that have sought to create smaller essential medicines list that is suitable for their respective nations [10-12]. However, the medicines used in palliative care settings, including hospices, hospital units or home care settings, may vary significantly according to their availability and accessibility in each country, as well as the international/national regulations and rules of each setting. For example, Cleary highlighted that despite holding a position on the essential medicines list, morphine was not readily available in appropriate dosage forms in East Africa and only became accessible in Bangladesh in 2014 [13]. Alternatively, efforts have been made in Australia to create the first-ever section in the Pharmaceutical Benefits Scheme for a specific group of patients with the inclusion of a palliative section that improves access to affordable palliative drugs outside of the hospital setting including morphine, clonazepam, methadone and hyoscine butylbromide [14]. Therefore, there may be inconsistencies relating to the patterns of prescribing and drug utilization within different palliative care settings internationally. There has been limited number of studies dedicated to drug utilization reviews, which identify and define the types of drugs used in palliative care settings in each country. Often studies are dedicated to one class of medicines, i.e. opioids, and do not take into account the entire pharmacotherapeutic spectrum $[15,16]$. It is important to understand the differences in drug use between countries to highlight any inequalities in medication management and to be able to better tailor strategies to improve palliative care provided to patients on a global scale. The purpose of this review was to provide an overview of medicine use in palliative care worldwide and to identify the most commonly used drugs in palliative care settings.

\section{Methods}

A quasi-systematic review was undertaken to identify relevant publications relating to drug utilization and prescription patterns in palliative care. A comprehensive search was performed using the MeSH terms palliative care, hospice, drug utilization, and prescription patterns. Inclusion criteria for the searches restricted the content to drug utilization studies that provided information on drug use patterns, prescriptions patterns or drug consumption and were written in the English language. The electronic databases searched to identify relevant articles included: MEDLINE, EMBASE, Scopus and Google Scholar. A date limit was applied so that only articles published from the year 2000-2018, were included. Articles were excluded if they only evaluated the use of a single class of medications i.e. opioids. All full-text articles were retrieved. Manual bibliographic searches were also performed to identify additional articles that were not found in the electronic searches. All articles were initially screened for inclusion in the review based on the title, then abstract and full text article as necessary.

\section{Results}

A total of 12 studies were found to meet the inclusion criteria and were included in the review. (Table 1) Studies were conducted in nine different countries, with one study analysing data from 11 different European countries - Austria $(n=1)$ [17], Brazil $(n=1)(18)$, Canada $(n=1)$ [19], Germany $(n=1)(17)$, Italy $(n=2)[20,21]$, Netherlands $(n=2)[4,22]$, Norway $(n=1)$ [23], Switzerland $(n=1)[17]$ and USA $(n=3)[3,24,25]$. The multinational study reported on medication use in Norway, Italy, Germany, the UK, Iceland, Sweden, Switzerland, Lithuania, Denmark, Finland and Greece [26]. It is apparent that there is a significant lack of published literature outlining drug usage in palliative care settings. However, three quarters (9/12) of the articles reviewed were published in the last 9 years (date range: 2011-2016) [3, 4, 18, 21-26]. The majority of studies used a retrospective means of data extraction $[3,4,19-21,23-26]$ and ranged in duration from 3 months to 5 years. As a result, the number of participants enrolled in the studies varied significantly, from 87 to 4252 patients. This may be also attributed to the number of settings included in each study, with some articles exploring large 
Table 1. Studies included in the review

\begin{tabular}{|c|c|c|c|c|c|c|}
\hline Author & Year & Country & $\begin{array}{l}\text { Palliative care } \\
\text { setting }\end{array}$ & $\begin{array}{l}\text { Duration } \\
\text { of study }\end{array}$ & $\begin{array}{l}\text { Number } \\
\text { of partici- } \\
\text { pants }\end{array}$ & Study design \\
\hline $\begin{array}{l}\text { Dwyer et al. } \\
\text { [24] }\end{array}$ & 2015 & USA & Hospice & 6 months & 2623 & $\begin{array}{l}\text { Retrospective cross- } \\
\text { sectional study }\end{array}$ \\
\hline $\begin{array}{l}\text { Fede et al. } \\
{[18]}\end{array}$ & 2011 & Brazil & $\begin{array}{l}3 \text { oncology clinics, } \\
\text { and } 1 \text { chemothera- } \\
\text { py clinic }\end{array}$ & 6 months & 87 & $\begin{array}{l}\text { Prospective, cross- } \\
\text { sectional survey }\end{array}$ \\
\hline $\begin{array}{l}\text { Hui et al. } \\
{[25]}\end{array}$ & 2015 & USA & $\begin{array}{l}\text { Acute palliative } \\
\text { care unit }\end{array}$ & 4 months & 100 & $\begin{array}{l}\text { Retrospective chart } \\
\text { review }\end{array}$ \\
\hline $\begin{array}{l}\text { Jansen et al. } \\
\text { [23] }\end{array}$ & 2014 & Norway & 3 Nursing homes & 5 years & 524 & $\begin{array}{l}\text { Historical cohort } \\
\text { study }\end{array}$ \\
\hline $\begin{array}{l}\text { Kotlinska- } \\
\text {-Lemieszek } \\
\text { et al. [26] }\end{array}$ & 2014 & $\begin{array}{l}\text { Norway, Italy, Germa- } \\
\text { ny, the UK, Iceland, } \\
\text { Sweden, Switzerland, } \\
\text { Lithuania, Denmark, } \\
\text { Finland, Greece }\end{array}$ & $\begin{array}{l}\text { Oncology wards, } \\
\text { palliative care } \\
\text { units/hospices, } \\
\text { outpatient clinics, } \\
\text { surgical wards }\end{array}$ & 4 years & 2282 & $\begin{array}{l}\text { Retrospective chart } \\
\text { review }\end{array}$ \\
\hline $\begin{array}{l}\text { Masman } \\
\text { et al. [4] }\end{array}$ & 2015 & The Netherlands & $\begin{array}{l}\text { Palliative care } \\
\text { centre }\end{array}$ & 1 year & 208 & $\begin{array}{l}\text { Retrospective co- } \\
\text { hort study }\end{array}$ \\
\hline $\begin{array}{l}\text { Mercandante } \\
\text { et al. [20] }\end{array}$ & 2001 & Italy & $\begin{array}{l}\text { Home palliative } \\
\text { care program }\end{array}$ & 2 years & 128 & $\begin{array}{l}\text { Retrospective co- } \\
\text { hort study }\end{array}$ \\
\hline $\begin{array}{l}\text { Nauck } \\
\text { et al. [17] }\end{array}$ & 2004 & $\begin{array}{l}\text { Austria, Germany } \\
\text { and Switzerland }\end{array}$ & Palliative care unit & 3 months & 1304 & $\begin{array}{l}\text { Prospective cohort } \\
\text { study }\end{array}$ \\
\hline $\begin{array}{l}\text { Raijmakers } \\
\text { et al. [21] }\end{array}$ & 2013 & Italy & $\begin{array}{l}\text { Hospital and ho- } \\
\text { spice units }\end{array}$ & 3 years & 195 & $\begin{array}{l}\text { Retrospective chart } \\
\text { review }\end{array}$ \\
\hline $\begin{array}{l}\text { Riechelmann } \\
\text { et al. [19] }\end{array}$ & 2007 & Canada & Palliative care clinic & 8 months & 255 & $\begin{array}{l}\text { Retrospective cross } \\
\text { - sectional study }\end{array}$ \\
\hline Sera et al. [3] & 2014 & USA & Hospice & 1 year & 4252 & $\begin{array}{l}\text { Retrospective } \\
\text { review }\end{array}$ \\
\hline $\begin{array}{l}\text { Van Norden- } \\
\text { nen et al. [22] }\end{array}$ & 2016 & The Netherlands & $\begin{array}{l}\text { Inpatient palliative } \\
\text { care facility }\end{array}$ & 6 months & 155 & $\begin{array}{l}\text { Observational, pro- } \\
\text { spective, multicen- } \\
\text { tre cohort study }\end{array}$ \\
\hline
\end{tabular}

databases or results of nationally representative sample surveys whereas others focussed on single palliative care units.

The criteria for enrolling patients into studies were relatively consistent and based on patient admission into a palliative care setting. The most commonly reported reasons for admission included advanced cancer/malignancies and pain $[3,4,17,18,22,25$, $26]$. The studies were based in different palliative care settings, including palliative care units in hospitals, nursing homes, home care and inpatient (stationary) hospices. Patients enrolled in studies mostly held diagnoses of cancer, dementia or heart disease/heart failure [17-19, 21-26]. Female patients comprised $38-65 \%$ of participant samples [4, 18-23, 25, 26]. The mean age of patient groups ranged from 5877.5 years of age [3, 17, 18, 20-22, 25, 26]. The median duration of stay in palliative care for patients ranged from 8 to 103 days [3, 4, 22, 23, 25].

\section{Commonly used drugs}

Overall, 5 most commonly prescribed classes of medications were reported as being non-opioid analgesics, opioids, laxatives, antipsychotics and sedatives $[3,4,17-26]$. Fig. 1 presents an overview of the 10 most commonly prescribed classes of medicines for palliative care patients. Within these classes of drugs, the most commonly prescribed individual medicines included morphine, haloperidol, laxatives and paracetamol $[3,4,17,20,21,23]$. Figure 2 presents an overview of 10 most commonly prescribed medications in palliative care settings. The most common route of administration was identified as subcutaneous, followed by oral and transdermal $[4,21]$.

Overall, it is apparent that drug usage across countries is relatively consistent with little to no differences in the types of drugs prescribed (Table 2). However, Kotlinska-Lemieszek et. al. identified in a study of drug 


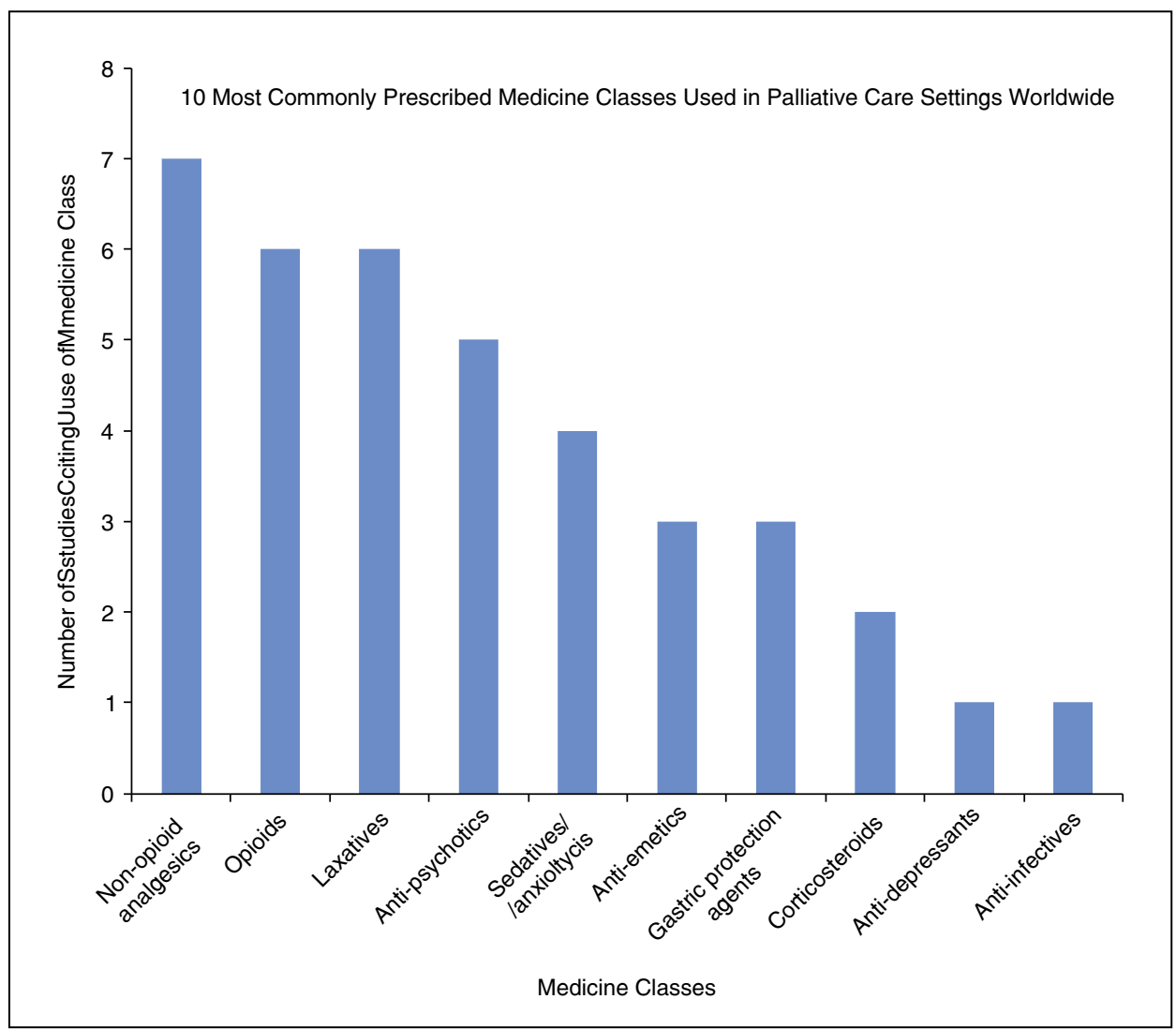

Figure 1. Ten most commonly used classes of drugs prescribed in palliative care settings worldwide

use in palliative care settings across 11 European countries that the use of non-opioid analgesics and corticosteroids differed between certain countries [26]. Corticosteroids were used in $33.6 \%$ of patients in Germany and the UK, however, were used in over $70 \%$ of patients in Italy and Sweden. Furthermore, $30.6 \%$ of patients in Italy were using non-opioids, in comparison to almost $70 \%$ of patients in Sweden and Switzerland [26].

\section{Discussion}

To our knowledge, this is the first review to provide an insight into medicines use in palliative care settings worldwide. The review presented both the therapeutic groups used in palliative care as well as individual drugs. Overall, it appears that the types of medicines used in palliative care settings on a global scale are similar, with high usage of non-opioid analgesics, opioids, sedatives and antipsychotics. As the majority of studies included in the review are from developed, European countries, this finding was anticipated. However, there is a significant lack of published literature outlining drug use in palliative care settings in general. Most studies are dedicated to single classes of medications i.e. opioids and do not explore the entire range of pharmacotherapy utilized in this patient population. Overall, it is difficult to ascertain the true extent of drug utilization in palliative care settings in each country as relevant literature from Australia, Asia, South America and a large proportion of Africa and Europe was not available.

Treatment of pain is a priority in palliative care as well as the management of dyspnea, delirium, anxiety, nausea, vomiting, constipation, and other symptoms. According to Franken et al. morphine, haloperidol and midazolam were identified as the three most commonly used drugs used in palliative care which was also indicated in our review [27]. When considering the application of pain relief, the review found that non-opioid analgesics including paracetamol, and opioids such as morphine and fentanyl were found to be used often in palliative care settings worldwide. It is unsurprising, that morphine, as a natural prototype of all opioids, was listed in most studies. Generally speaking, it, is used for pain management in the treatment of cancer, during palliative care typically via oral route with controlled-release formulations for the treatment of chronic pain, as well as in immediate-release solutions 


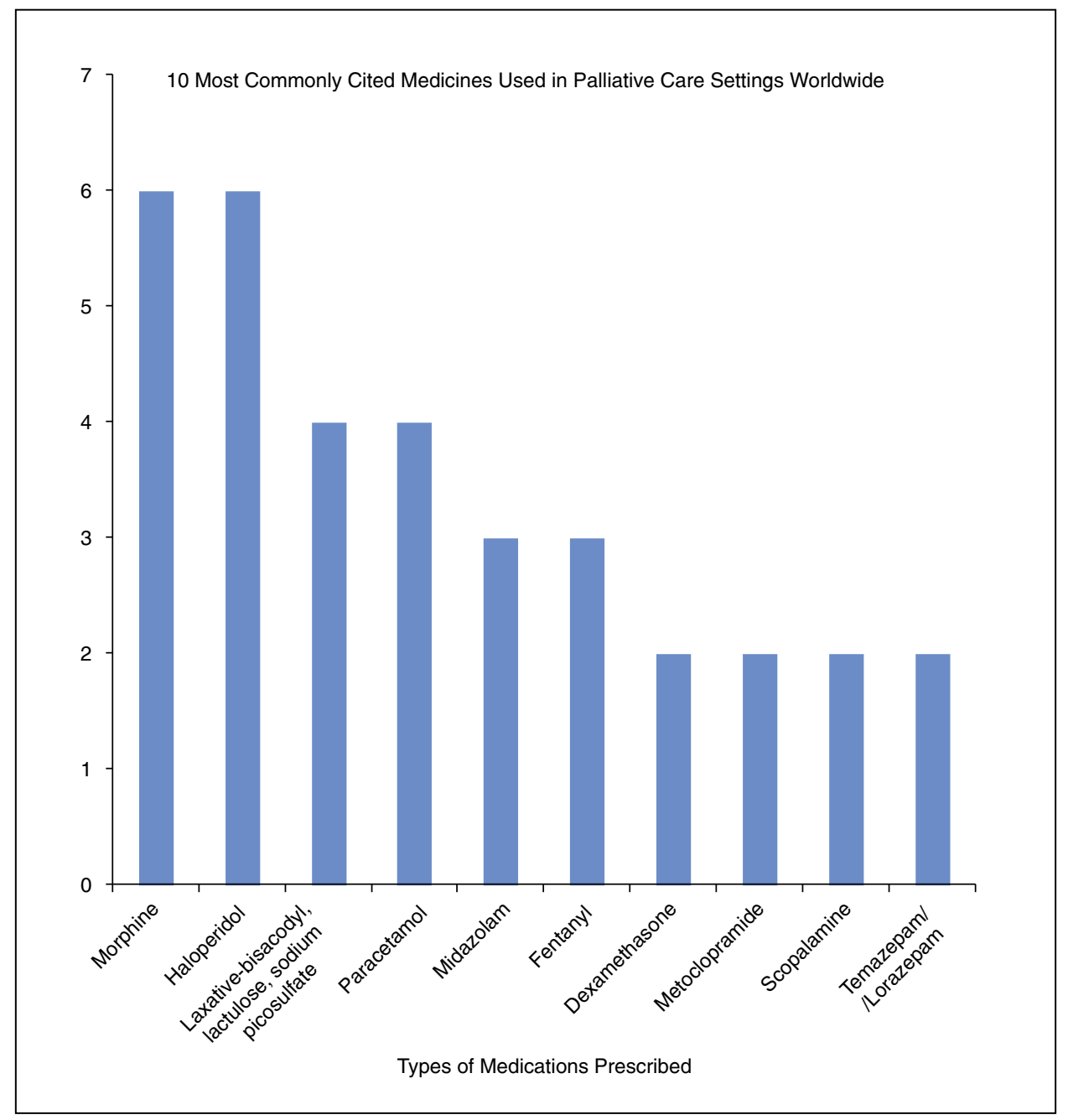

Figure 2. Most commonly cited drugs used in palliative care settings worldwide

Table 2. Drug use by country

\begin{tabular}{|c|c|}
\hline Country & Most commonly used drugs cited in articles \\
\hline Austria, Germany, Switzerland [17] & Dipyrone, Morphine, Fentanyl \\
\hline Brazil [18] & Paracetamol, Dipyrone \\
\hline Canada [19] & Opioids, Laxatives, Corticosteroids \\
\hline Italy $[20,21]$ & Morphine, Ranitidine, Midazolam \\
\hline The Netherlands $[4,22]$ & $\begin{array}{l}\text { Morphine, Midazolam, Haloperidol, Paracetamol, Fentanyl, Ma- } \\
\text { crogol }\end{array}$ \\
\hline Norway [23] & Morphine, Midazolam, Glycopyronium \\
\hline USA $[3,24]$ & Paracetamol, Lorazepam, Morphine, Haloperidol \\
\hline $\begin{array}{l}\text { Multinational study - Norway, Italy, Germany, } \\
\text { UK, Iceland, Sweden, Switzerland, Lithuania, } \\
\text { Denmark, Finland, Greece [26] }\end{array}$ & Opioids, Proton Pump Inhibitors, Laxatives \\
\hline
\end{tabular}

or tablets for the management of breakthrough pain episodes. Morphine is also used in the symptomatic management of dyspnoea. The findings also showed that fentanyl was commonly used, which may be due to its outstanding properties as a small molecule with lipophilicity, allowing the use of this opioid for the management of chronic pain in patches via the transdermal route. 
It is important to consider that the level of opioid consumption is closely related to the ease of access to opioids in each country. Duthey et al. conducted a survey determining the levels of opioid consumption on a global scale, and included countries that were analyzed in this review including Canada, Germany, Switzerland and the USA [28]. The levels of consumption were compared with the Adequacy of Consumption Measure (ACR) [28]. Interestingly, non-European countries including Canada and the USA presented the highest levels of opioid consumption, with the consumption of morphine equivalents per capita listed as $657.27 \mathrm{mg}$ in Canada, and $481.99 \mathrm{mg}$ in the USA, indicating ready access to opioids [28]. In Italy, the Netherlands and Norway the consumption of opioids was estimated as being moderate (ACR 30-100\%) [28]. Among these countries, Italy indicated the lowest levels of opioid consumption: $71.06 \mathrm{mg}$ of morphine equivalents per capita and an ACM of $34.01 \%$, however was still deemed satisfactory [28]. The study concluded that the analyzed countries did not experience obvious barriers to opioid access, which may then have a positive influence on pain treatment [28].

Haloperidol as a typical antipsychotic was also seen to be used in palliative care settings often. However, its use for delirium in palliative care patients is debatable. In a placebo-controlled randomized clinical trial, haloperidol was compared to risperidone (atypical antipsychotic) and to a placebo in the treatment of delirium in patients receiving palliative care [29]. Interestingly, the study concluded that antipsychotic drugs are not useful in reducing the symptoms of delirium associated with distress in palliative patients [29]. The authors showed that behaviour, communication, and perceived symptoms of delirium were significantly greater in the group of patients treated with antipsychotics (risperidone or haloperidol) [29]. However in contrast, a large meta-analysis (58 randomized controlled trials, 9603 patients) indicated that haloperidol with the addition of lorazepam experienced the best response rate for the pharmacological treatment of delirium in general [30]. In practice, haloperidol is often recommended in combination with midazolam for refractory delirium in palliative care sedation [31]. This combination has been shown to be more effective in the treatment of agitation in palliative care patients than haloperidol alone [32]. Our findings highlighted that midazolam as an individual pharmacotherapy also rated highly amongst the most commonly used dru$\mathrm{gs}$. It is indicated in palliative care patients for anxiety, agitation and as an anticonvulsant. Midazolam can be also used in the management of dyspnoea and hiccup. However, morphine and metoclopramide are regarded as being first choice therapies of the symptomatic treatment of dyspnoea and hiccup, respectively [33].
The findings of the review highlighted the number of drugs used in palliative care settings worldwide. There was a perceived difference between EU countries, where the number of medicines was approximately 5 per patient and the USA, where one study listed 10 different drugs for use in one patient. These differences may be attributed as being a consequence of the many guidelines available in the USA recommending treatment for particular medical conditions, in most cases suggesting 2 or 3 drugs rather than monotherapy to increase the efficacy of the treatment. However, from a perspective of palliative care there is limited to no appropriate evidence guiding the use of therapy in patients with many different coexisting symptoms [34]. As a result this leads to polypharma$c y$, defined as the use of more than 5 medications in a single patient at the same time [35]. Polypharmacy is a very common issue among palliative care patients because of the high prevalence of multiple conditions which may require pharmacological management. Often, the adverse effects of one medication results in the need for the addition of other drugs to manage the subsequent symptoms i.e. treatment with opioids often requires the addition of laxatives to prevent or treat opioid-induced constipation. It is important to note that polypharmacy can lead to many negative outcomes including the exacerbation of adverse effects and the potential to increase the incidence of drug drug interactions $[36,37]$. According to the Unnecessary Drug Use Measure, (a tool evaluating the proper use of drugs according to their indication, efficacy and therapeutic duplication), there is a need to analyse, and if possible, decrease the number medicines prescribed for a single patient to minimise the possibility of inappropriate medications use [38].

\section{Limitations of the review}

The main limitation of this review is the lack of recently published literature outlining the prescription patterns of drugs used in palliative care settings, limiting the analysis that could be done and also the comparisons between countries. The findings may not be representative of palliative care settings in each country and should be interpreted with caution. However, this study can inform future research to capture a more comprehensive view of medication use in palliative care settings.

\section{Conclusions}

Overall, medication use is similar in palliative care settings worldwide, with a strong emphasis on pain relief. However, the 12 articles reviewed in this paper 
do not give a sufficient summary of medication use and may provide a biased insight into drug utilization. Given the diversity of practice, it is important to provide clear descriptions of prescription patterns within palliative care and compare drug utilization across different clinical settings and countries to identify whether there are any differences in practice. There is a need for future research to focus on canvassing a more comprehensive overview of drug use in palliative care settings.

\section{References}

1. World Health Organization. Palliative Care 2018. http:// www.who.int/en/news-room/fact-sheets/detail/palliativecare.

2. Astolfi J. Palliative Care. In: DiPiro JT, Talbert RL, Yee GC, Matzke GR, Wells BG, Posey LM. ed. Pharmacotherapy: A Pathophysiologic Approach. The McGraw-Hill Companies, New York 2014.

3. Sera L, McPherson ML, Holmes HM. Commonly prescribed medications in a population of hospice patients. Am J Hosp Palliat Care. 2014; 31(2): 126-131, doi: 10.1177/1049909113476132, indexed in Pubmed: 23408370.

4. Masman AD, van Dijk M, Tibboel D, et al. Medication use during end-of-life care in a palliative care centre. Int J Clin Pharm. 2015; 37(5): 767-775, doi: 10.1007/s11096-0150094-3, indexed in Pubmed: 25854310.

5. CareSearch. Palliative Medications 2017. https://www. caresearch.com.au/caresearch/tabid/1554/Default.aspx.

6. Kwon JH, Kim MJi, Bruera S, et al. Off-Label Medication Use in the Inpatient Palliative Care Unit. J Pain Symptom Manage. 2017; 54(1): 46-54, doi: 10.1016/j.jpainsymman.2017.03.014, indexed in Pubmed: 28479415.

7. Lima LDe, Doyle D. The International Association for Hospice and Palliative Care List of Essential Medicines for Palliative Care. Journal of Pain \& Palliative Care Pharmacotherapy. 2009; 21(3): 29-36, doi: 10.1080/j354v21n03 05.

8. World Health Organization. WHO Model List of Essential Medicines 2013 . http://apps..int/iris/bitstream/handle/10665/93142/EML_18_eng (October 2013).

9. World Health Organization. Essential Medicines in Palliative Care 2013 . http://wwww.who.int/selection_medicines/committees/expert/19/applications/PalliativeCare_8_A_R.pdf.

10. Good PD, Cavenagh JD, Currow DC, et al. What are the essential medications in pallative care? - a survey of Australian palliative care doctors. Aust Fam Physician. 2006; 35(4): 261-264, indexed in Pubmed: 16642246.

11. Lindqvist $O$, Lundquist $G$, Dickman $A$, et al. OPCARE9. Four essential drugs needed for quality care of the dying: a Delphi-study based international expert consensus opinion. J Palliat Med. 2013; 16(1): 38-43, doi: 10.1089/jpm.2012.0205, indexed in Pubmed: 23234300.

12. Tait $P$, Morris B, To T. Core palliative medicines: meeting the needs of non-complex community patients. Aust Fam Physician. 2014; 43(1): 29-32, indexed in Pubmed: 24563890.

13. Cleary J. Essential medicines in palliative care. Palliative Medicine. 2014; 28(4): 291-292, doi: 10.1177/0269216314527036.

14. Hardy J. Quality use of medicines for palliative care. Palliative Care and Cancer. 2007; 31(1): e3-e5.

15. Ziegler L, Mulvey $M$, Blenkinsopp $A$, et al. Opioid prescribing for patients with cancer in the last year of life: a longitudinal population cohort study. Pain. 2016; 157(11):
2445-2451, doi: 10.1097/j.pain.0000000000000656, indexed in Pubmed: 27626624.

16. Higginson IJ, Gao W. Opioid prescribing for cancer pain during the last 3 months of life: associated factors and 9-year trends in a nationwide United Kingdom cohort study. J Clin Oncol. 2012; 30(35): 4373-4379, doi: 10.1200/JCO.2012.42.0919, indexed in Pubmed: 23109701.

17. Nauck F, Ostgathe C, Klaschik E, et al. Working Group on the Core Documentation for Palliative Care Units in Germany. Drugs in palliative care: results from a representative survey in Germany. Palliat Med. 2004; 18(2): 100-107, doi: 10.1191/0269216304pm852oa, indexed in Pubmed: 15046406.

18. Fede A, Miranda M, Antonangelo D, et al. Use of unnecessary medications by patients with advanced cancer: cross-sectional survey. Support Care Cancer. 2011; 19(9): 1313-1318, doi: 10.1007/s00520-010-0947-1, indexed in Pubmed: 20652603.

19. Riechelmann RP, Krzyzanowska MK, O'Carroll A, et al. Symptom and medication profiles among cancer patients attending a palliative care clinic. Support Care Cancer. 2007; 15(12): 1407-1412, doi: 10.1007/s00520-007-02538, indexed in Pubmed: 17429699.

20. Mercadante S, Fulfaro F, Casuccio A. Pattern of drug use by advanced cancer patients followed at home. J Palliat Care. 2001; 17(1): 37-40, indexed in Pubmed: 11324183.

21. Raijmakers NJH, van Zuylen L, Furst CJ, et al. Variation in medication use in cancer patients at the end of life: a cross-sectional analysis. Support Care Cancer. 2013; 21(4): 1003-1011, doi: 10.1007/s00520-012-1619-0, indexed in Pubmed: 23064901.

22. van Nordennen RT, Lavrijsen JCM, Heesterbeek MJ, et al. Changes in Prescribed Drugs Between Admission and the End of Life in Patients Admitted to Palliative Care Facilities. J Am Med Dir Assoc. 2016; 17(6): 514-518, doi: 10.1016/j. jamda.2016.01.015, indexed in Pubmed: 26935532.

23. Jansen $\mathrm{K}$, Schaufel MA, Ruths $\mathrm{S}$. Drug treatment at the end of life: an epidemiologic study in nursing homes. Scand J Prim Health Care. 2014; 32(4): 187-192, doi: 10.3109/02813432.2014.972068, indexed in Pubmed: 25363144.

24. Dwyer LL, Lau DT, Shega JW. Medications That Older Adults in Hospice Care in the United States Take, 2007. J Am Geriatr Soc. 2015; 63(11): 2282-2289, doi: 10.1111/jgs.13795, indexed in Pubmed: 26531894.

25. Hui D, Li Z, Chisholm GB, et al. Changes in medication profile among patients with advanced cancer admitted to an acute palliative care unit. Support Care Cancer. 2015; 23(2): 427-432, doi: 10.1007/s00520-014-2390-1, indexed in Pubmed: 25123192.

26. Kotlinska-Lemieszek A, Paulsen O, Kaasa S, et al. Polypharmacy in patients with advanced cancer and pain: a European cross-sectional study of 2282 patients. J Pain Symptom Manage. 2014; 48(6): 1145-1159, doi: 10.1016/j.jpainsymman.2014.03.008, indexed in Pubmed: 24780183.

27. Franken LG, de Winter BCM, van Esch HJ, et al. Pharmacokinetic considerations and recommendations in palliative care, with focus on morphine, midazolam and haloperidol. Expert Opin Drug Metab Toxicol. 2016; 12(6): 669-680, doi: 10.1080/17425255.2016.1179281, indexed in Pubmed: 27081769.

28. Duthey B, Scholten W. Adequacy of opioid analgesic consumption at country, global, and regional levels in 2010, its relationship with development level, and changes compared with 2006. J Pain Symptom Manage. 2014; 47(2): 283-297, doi: 10.1016/j.jpainsymman.2013.03.015, indexed in Pubmed: 23870413. 
29. Agar MR, Lawlor PG, Quinn S, et al. Efficacy of Oral Risperidone, Haloperidol, or Placebo for Symptoms of Delirium Among Patients in Palliative Care: A Randomized Clinical Trial. JAMA Intern Med. 2017; 177(1): 34-42, doi: 10.1001/jamainternmed.2016.7491, indexed in Pubmed: 27918778.

30. Wu YC, Tseng PT, Tu YK, et al. Association of Delirium Response and Safety of Pharmacological Interventions for the Management and Prevention of Delirium: A Network Meta-analysis. JAMA Psychiatry. 2019; 76(5): 526-535, doi: 10.1001/jamapsychiatry.2018.4365, indexed in Pubmed: 30810723.

31. Garetto F, Cancelli F, Rossi R, et al. Palliative Sedation for the Terminally III Patient. CNS Drugs. 2018; 32(10): 951-961, doi: 10.1007/s40263-018-0576-7, indexed in Pubmed: 30259395.

32. Ferraz Gonçalves JA, Almeida A, Costa I, et al. Comparison of Haloperidol Alone and in Combination with Midazolam for the Treatment of Acute Agitation in an Inpatient Palliative Care Service. J Pain Palliat Care Pharmacother. 2016; 30(4): 284-288, doi: 10.1080/15360288.2016.1231733, indexed in Pubmed: 27749141.

33. Jeon YS, Kearney AM, Baker PG. Management of hiccups in palliative care patients. BMJ Support Palliat Care. 2018;
8(1): 1-6, doi: 10.1136/bmjspcare-2016-001264, indexed in Pubmed: 28705925.

34. American Geriatrics Society Exert Panel on the Care of Older Adults with Multimorbidity. Guiding rinciles for the care of older adults with multimorbidity: an aroach for clinicians. J Am Geriatr Soc. 2012: E1-E25.

35. Nieder C, Mannsăker B, Pawinski A, et al. Polypharmacy in Older Patients $\geq 70$ Years Receiving Palliative Radiotherapy. Anticancer Res. 2017; 37(2): 795-799, doi: 10.21873/anticanres.11379, indexed in Pubmed: 28179332.

36. By the American Geriatrics Society 2015 Beers Criteria Update Expert Panel. American Geriatrics Society 2015 Updated Beers Criteria for Potentially Inappropriate Medication Use in Older Adults. J Am Geriatr Soc. 2015; 63(11): 2227-2246, doi: 10.1111/jgs.13702, indexed in Pubmed: 26446832.

37. Bourgeois FT, Shannon MW, Valim C, et al. Adverse drug events in the outpatient setting: an 11-year national analysis. Pharmacoepidemiol Drug Saf. 2010; 19(9): 901-910, doi: 10.1002/pds.1984, indexed in Pubmed: 20623513.

38. McGrath K, Hajjar ER, Kumar C, et al. Deprescribing: A simple method for reducing polypharmacy. J Fam Pract. 2017; 66(7): 436-445, indexed in Pubmed: 28700758. 